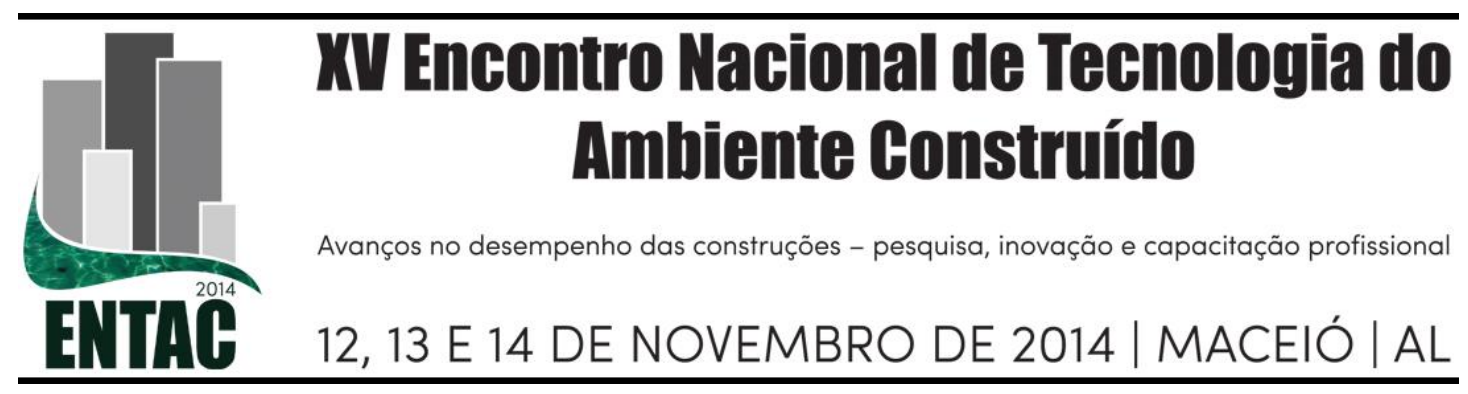

\title{
ESTADO DA ARTE DOS SISTEMAS CONSTRUTIVOS DE UNIDADES PENAIS DE REGIME FECHADO NO BRASIL
}

\author{
TENÓRIO FILHO, José Roberto (1); LIMA ${ }^{1}$, Suzann Flávia Cordeiro de (2); \\ CARVAlHO NETO, Aloísio Batista de (3); CORREIA, Dayane Alexandre (4); \\ LEITE, Débora Teixeira Correia (5); LIMA, Camila Costa de (6); MELO, \\ Hedhyliana Walkyria Rodrigues de (7);
}

(1) Universidade Federal de Alagoas, e-mail: jr.roberto@ hotmail.com (2) Universidade Federal de

Alagoas, e-mail: suzanncordeiro@hotmail.com

\begin{abstract}
RESUMO
O cenário atual do sistema prisional brasileiro é caracterizado, dentre outros, pela insuficiência da capacidade de vagas, extremamente inferior à demanda existente. Tal realidade traz à tona uma superpopulação carcerária. Tempo de execução, qualidade e desempenho da estrutura em utilização e custos envolvidos na implantação de unidades penitenciárias configuram grandes obstáculos para a eficiência da política pública brasileira, quando o assunto é arquitetura penal. O estudo apresentado possui caráter exploratório e objetiva apresentar um resumo sobre o contexto geral dos sistemas construtivos de unidades penais de regime fechado a influência de novas tecnologias no desempenho destes estabelecimentos enquanto espaço construído. Adotou-se como procedimentos metodológicos a revisão bibliográfica de conceitos de humanização (para um melhor entendimento do espaço prisional não sendo contudo, objeto de foco deste estudo) e arquitetura prisional, análise de projetos arquitetônicos de unidades penais e os principais materiais e sistemas construtivos atualmente adotados. Iniciando pelas grandes cadeias públicas do Brasil Colônia com a utilização marcante da construção em pedra, argamassas de cal e barro e, por vezes, óleo de baleia como material aglomerante caracteriza-se um sistema bastante rústico, construções insalubres, com técnicas de execução rudimentares e intermináveis prazos de execução. Nas últimas décadas verifica-se verdadeira revolução dos sistemas, com o advento da utilização de sistemas préfabricados em concreto na execução de unidades, reduzindo o tempo de execução das obras e aumentando exponencialmente a qualidade, segurança e durabilidade das construções. Sobre questões de desempenho dos materiais, os sistemas estudados destacam-se em segurança, agilidade de execução e qualidade da estrutura. Ressalta-se que a busca por sistemas inovadores não é suficiente, o custo de aplicação de novas tecnologias pode ser fator decisivo em sua escolha para aplicação, a falta de pesquisas e difusão dos métodos de produção e aplicação destes sistemas acaba gerando uma barreira para a diminuição dos custos envolvidos e aplicação destas soluções.
\end{abstract}

Palavras-chave: Arquitetura penal, Sistemas construtivos, Desempenho das edificações.

\begin{abstract}
The current scenario of the Brazilian prison system is characterized, among others, by insufficient capacity of vacancies, vastly inferior to the existing demand. This reality brings out a prison-overcrowding situation. Construction time, quality and performance of the structure in use and costs involved in settling penitentiary units constitute major obstacles to the efficiency of Brazilian public policy, when it comes to prison architecture issues. The present study has exploratory nature and intends to present a brief and general context about the building systems of those units and their impact on the performance of these establishments as a built space. As methodological procedures, it was performed bibliographic reviews of concepts regarding to humanization and prison architecture, analysis of architectural projects and the main construction materials and systems currently in use. Beginning with large public prison of colonial
\end{abstract}

\footnotetext{
${ }^{1}$ Orientadora da pesquisa e coordenadora do Núcleo de Estudos de Projetos Especiais (NuPES)
} 
Brazil with a large use of building stones, lime based mortars and clay and sometimes whale oil as a binder material; takes place a very rustic system, unhealthy buildings with rudimentary techniques for its implementation, beyond endless deadlines. In recent decades it has been noticed a real revolution, with the advent of precast concrete systems in the implementation of units, reducing the time of the works and exponentially increasing the quality, safety and durability of buildings. Concerning to the material performance, the studied systems stand out in safety, speed of execution and quality of the structure. It is emphasized that the search for innovative systems itself is not enough, the cost of implementing new technologies can be a decisive factor in its choice of application, the lack of research and dissemination of methods of production and application of these systems ends up creating a barrier to lower costs involved and implementing these solutions.

Keywords: Prison architecture, Building systems, Quality and performance of buildings.

\section{INTRODUÇÃ̃O}

O cenário atual do sistema prisional brasileiro é caracterizado, dentre outros, pela insuficiência da capacidade de vagas, extremamente inferior à demanda existente. Tal realidade traz à tona uma superpopulação carcerária e uma série de mandados de prisão não cumpridos, em sua maioria, pela falta de vagas em estabelecimentos penais. Fatores como tempo de execução, qualidade e desempenho da estrutura em utilização e custos envolvidos na implantação de unidades penitenciárias têm sido um grande obstáculo para a eficiência da política pública brasileira, quando o assunto é arquitetura penal.

Segundo dados de pesquisa publicada pelo International Centre for Prison Studies (ICPS), da Universidade de Essex, na Inglaterra (divulgadas pelo folhetim eletrônico O GLOBO em edição de janeiro de 2014) a população carcerária brasileira passa de 548 mil presos. A capacidade do sistema é de, aproximadamente, 310 mil vagas, apresentando um déficit de, aproximadamente, 238 mil vagas.

No caso específico da Arquitetura Penal, a constatação de alguns conceitos por vezes é desconhecida pela sociedade, fato que dificulta a compreensão do sistema penitenciário, trazendo à tona a necessidade de apresentá-los, a fim de poder descrevê-lo como elemento de análise para o planejamento dos espaços penais.

Por se tratar de espaço de segurança, considerando-se a necessidade de cuidadosos controles e rigorosa disciplina, segundo nos dizem os gestores do sistema prisional, considera-se, aqui, a necessidade de compreender melhor quais as estratégias e soluções espaciais necessárias à segurança das unidades.

Desde a implementação de Resoluções sobre projetos de estabelecimentos penais no país, que coincidem com a atuação do Conselho Nacional de Política Criminal e Penitenciária (CNPCP/MJ), busca-se a aplicação de materiais e sistemas construtivos que atendam satisfatoriamente aos fatores de segurança e habitabilidade desejados.

Iniciando pelas grandes cadeias públicas do Brasil Colônia (Figuras 1a e 1b) com a utilização marcante da construção em pedra, argamassas de cal e barro e, por vezes, o óleo de baleia como material aglomerante, podendo apresentar paredes com espessura de até $1,5 \mathrm{~m}$ na tentativa de evitar o colapso estrutural devido às elevadas cargas dos pavimentos térreo e superior e das cobertas sobre as paredes perimetrais (Figura 2). Tais evidencias apenas reforçam as características de um sistema bastante rústico configurando construções insalubres, com técnicas de execução rudimentares e intermináveis prazos de execução. 


\section{Figura 1 - (a) Casa de câmara e cadeia de Ouro Preto. (b) Casa de câmara e cadeia de Salvador}
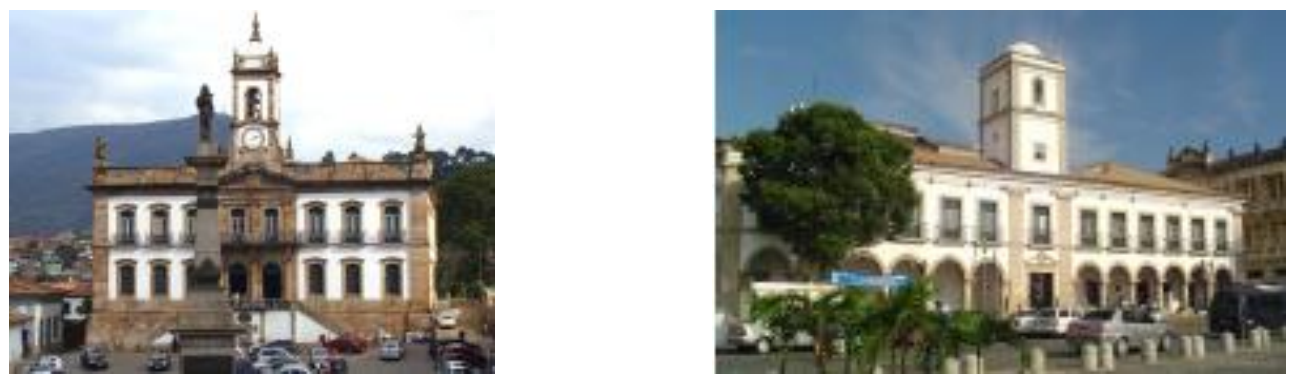

Fonte: Viana (2009)

Figura 2 - Variação de espessura das paredes em função do comportamento mecânico da estrutura
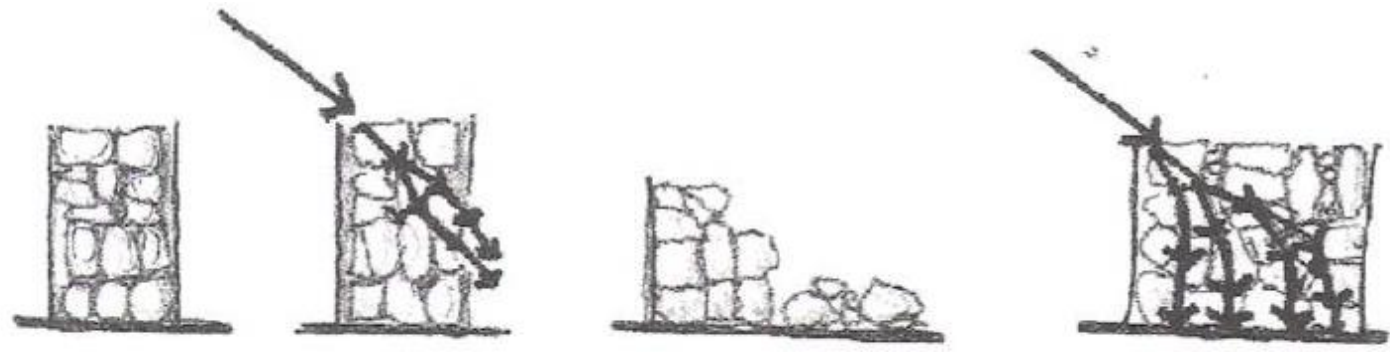

Fonte: Piccolo (2006)

Tal sistema foi gradualmente substituído pela alvenaria de vedação em tijolos cerâmicos, trazendo uma maior agilidade na execução da obra e um maior controle sobre o sistema construtivo, e posteriormente, avançou para o uso do bloco de concreto grauteado, no intuito de aumentar a resistência.

Das quatro últimas décadas até os dias atuais tem-se verificado uma verdadeira revolução dos sistemas, com o advento da utilização do concreto na execução de muros e paredes, reduzindo o tempo de execução das obras e aumentando exponencialmente a qualidade, segurança e durabilidade das construções.

O desenvolvimento de novos materiais, como concretos de alto desempenho e a difusão dos sistemas pré-moldados, possibilitou um salto imensurável na linha do tempo das construções penitenciárias. Obras executadas em anos são realizadas em alguns meses; paredes que antes possuíam até $1,5 \mathrm{~m}$ de espessura foram substituídas por blocos e placas de concreto pré-moldados com até $8 \mathrm{~cm}$ de espessura; ausência de elementos de aço antes utilizados como armas pelos próprios detentos e até mesmo sensores de fibra ótica capazes de notificar tentativas de fuga são algumas das inúmeras vantagens dos novos sistemas.

A evolução dos métodos citados mostra-se como elemento de fundamental importância dentro da problemática apresentada, sendo determinante na melhoria dos estabelecimentos penitenciários enquanto espaços de custodiamento e desempenho de segurança. A análise da evolução dos sistemas construtivos para estabelecimentos penais também pode permitir, entre outros, compreender como desenvolver novas técnicas de 
avaliação de desempenho específicas para materiais construtivos, buscando especificações técnicas como estratégias para a humanização destes espaços, aspecto pouco considerado na atual concepção de projetos penais.

Neste sentido, o estudo apresentado possui caráter exploratório e compõe parte dos resultados de pesquisa de iniciação científica intitulada Estudo das tipologias arquitetônicas de unidades penais de regime fechado, objetivando apresentar o impacto da evolução dos sistemas construtivos de unidades penais de regime fechado no desempenho destes estabelecimentos enquanto espaço construído.

Adotou-se como procedimentos metodológicos a revisão bibliográfica de conceitos de humanização e arquitetura prisional, mapeamento das unidades penais brasileiras com base na tipologia arquitetônica utilizada e no sistema construtivo empregado (através da ferramenta (C) 2014 Google Maps, sendo analisadas um total de 211 unidades distribuídas por todo o país), análise de projetos arquitetônicos e especificações técnicas de unidades penais com foco nos principais materiais e sistemas construtivos atualmente adotados (de acordo com as recomendações de desempenho e utilização presentes na resolução 09/2011 do CNPCP/MJ).

As tipologias arquitetônicas prisionais podem ser classificadas segundo critérios a) de segurança, do nível mínimo ao máximo, como as supermax e b) de gestão, que são prisões estaduais, federais e prisões público-privadas e prisões híbridas, porém estas classificações não consideram a função e o lugar da prisão na sociedade.

Em análises feitas no banco de projetos arquitetônicos do Departamento Penitenciário Nacional do Ministério da Justiça (DEPEN/MJ), pode-se observar grupos de caracteres semelhantes em alguns partidos arquitetônicos: poste telegráfico, panótico, convento, compacto (que se consolidaram a partir da década de 60) e, atualmente, os projetos préfabricados, que correspondem a mais de 80 estabelecimentos penais, no Brasil.

O setor de pré-fabricados de concreto, acompanhando o desenvolvimento da economia brasileira e o crescimento da construção, tem evoluído de forma expressiva nos últimos anos e contribuído com a ampliação da base industrial, imobiliária e de infraestrutura do país. Segundo dados publicados no anuário 2012 da Associação Brasileira da Construção Industrializada de Concreto (ABIC), o setor apresentou um crescimento de $15 \% \mathrm{em}$ volume de produção no ano de 2012.

Com base na análise de unidades realizadas verificou-se que os sistemas pré-fabricados, identificados nas tipologias arquitetônicas panótica e monobloco, constituem $33 \%$ dos sistemas utilizados nas unidades brasileiras, com destaque para a região sul, com um total de $56 \%$ das unidades pesquisadas.

Dados do ministério da justiça, apresentados no Programa Nacional de Melhoria do Sistema Prisional revelam que ainda é caro utilizar a pré-fabricação na maioria dos casos (Quadro 1), embora, a depender da especificação do sistema utilizado, o custo inicial pode ser rapidamente compensado.

Destaca-se, neste quadro comparativo, a equivalência de custos nas construções de novos estabelecimentos penais, no que se refere aos estabelecimentos pré-moldados, enquanto há uma variação de valores nos métodos construtivos convencionais, em que os projetos financiados pelo Governo Federal apresentam mais de 10\% de diferença nos custos/vaga, em relação aos projetos com recursos dos governos estaduais. 


\section{Quadro 1 -Comparativo do custo por vaga}

\begin{tabular}{|c|c|c|c|c|}
\hline & & $\begin{array}{c}\text { Método } \\
\text { Construtivo }\end{array}$ & $\begin{array}{c}\text { Projetos } \\
\text { financiados pelo } \\
\text { DEPEN } \\
\end{array}$ & $\begin{array}{c}\text { Projetos com recursos } \\
\text { das UFs* }\end{array}$ \\
\hline \multirow{4}{*}{ Ampliação } & \multirow{2}{*}{ Cadeia Pública } & Pré-moldado & - & $16.000,00 * *$ \\
\hline & & Convencional & $19.000,00$ & $8.000,00$ \\
\hline & \multirow{2}{*}{ Penitenciária } & Pré-moldado & - & $16.000,00 * *$ \\
\hline & & Convencional & $23.000,00$ & $26.000,00$ \\
\hline \multirow{4}{*}{ Construção } & \multirow{2}{*}{ Cadeia Pública } & Pré-moldado & $42.000,00$ & $42.000,00$ \\
\hline & & Convencional & $38.000,00$ & $33.000,00$ \\
\hline & \multirow{2}{*}{ Penitenciária } & Pré-moldado & $52.000,00$ & $53.000,00$ \\
\hline & & Convencional & $45.000,00$ & $33.000,00$ \\
\hline
\end{tabular}

* Sem garantia de cumprimento das diretrizes do CNPCP

** Somente o módulo vivência (6 por cela)

Fonte: Apresentação do Programa Nacional de Melhoria do Sistema Prisional. Ministério da Justiça (2011)

Dentre os projetos que utilizam de tais sistemas, destacam-se duas tipologias preponderantes, descritas a seguir:

\subsection{Sistema A}

Construído de acordo com padrões de tipologias norte-americanas, baseado em elementos pré-moldados em concreto armado com resistência média à compressão de $60 \mathrm{MPa}$, este sistema configura-se como tipologia arquitetônica modular, em formato T (Figura 3 ) em que a população carcerária é controlada por estação elevada (a 1,50 m do nível do piso) localizada na intersecção dos módulos (Figura 4).

Figura 3 - Tipologia semi-cruz ou T

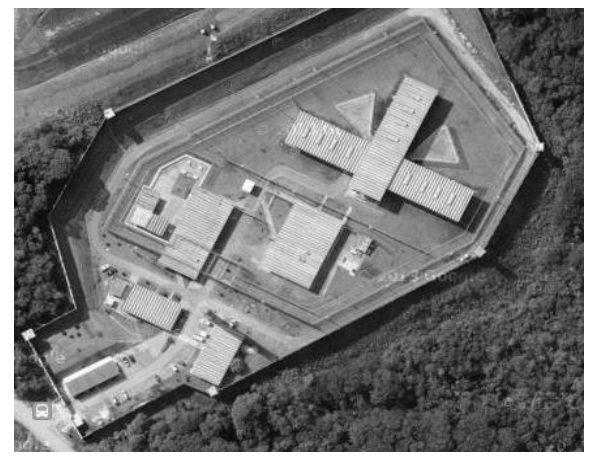

Fonte: Google Maps (2014)
Figura 4 - Posto de controle elevado

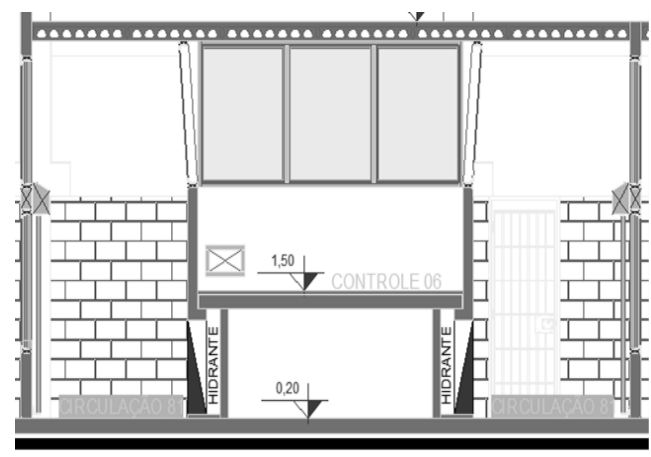

Fonte: Projeto arquitetônico com base no sistema A. DM Construtora (2011)

O sistema é baseado na fabricação de celas duplas que são concretadas de maneira a compor um bloco monolítico. Toda a concretagem e montagem das unidades realiza-se em fábrica e para o canteiro são transportadas as unidades prontas para montagem. Do acoplamento dos blocos podem-se obter pavimentos superiores sendo destinada uma passarela externa para circulação da vigilância, com laje de área técnica acima das celas (Figura 5). 


\section{Figura 5 - Configuração de módulos com pavimento superior}

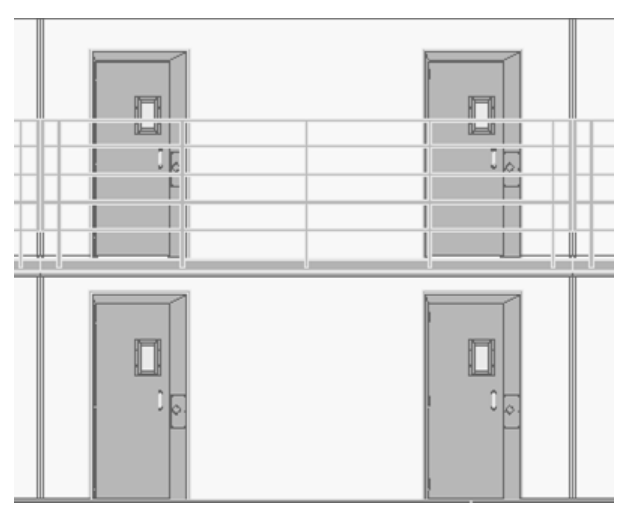

Fonte: Projeto arquitetônico com base no sistema A. DM Construtora (2011)

As paredes das celas apresentam espessura de $15 \mathrm{~cm}$ e a laje de piso de $50 \mathrm{~cm}$ para evitar tentativas de fugas através de escavações. Os setores administrativos, de serviços e saúde são construídos de maneira diferente. A estrutura é composta por pilares e vigas de concreto, também pré-fabricadas e, transportadas ao local da obra apenas para locação e montagem. A vedação vertical destes espaços é executada com blocos de concreto de dimensões 14x39x19 cm.

Tratando-se de um sistema em que os blocos de celas são concretados em fôrma tipo caixa dupla, de maneira a formar uma estrutura monolítica, todo o projeto da área de vivência dos detentos é realizado de maneira modulada, em que os ambientes são todos resultados da coordenação de ambientes de base, como uma repetição em série de módulos (Figura $6)$.

Figura 6 - Modulação das celas

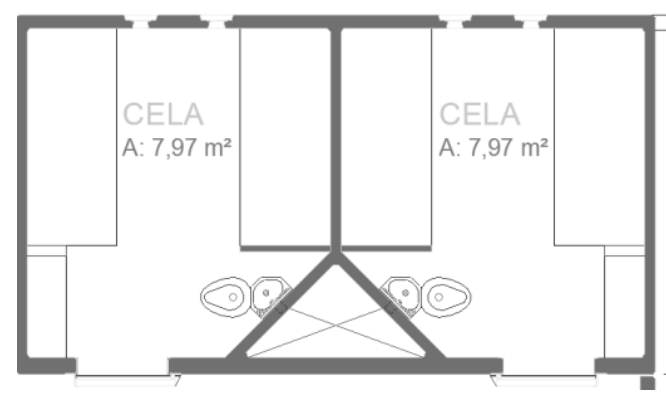

Fonte: Projeto arquitetônico com base no sistema A. DM Construtora (2011)

Apesar de facilitar a produção e montagem dos módulos, o sistema coordenado acaba inviabilizando o desenvolvimento de tipologias arquitetônicas mais flexíveis fazendo-se necessária a utilização de técnicas baseadas em sistemas convencionais para finalização da estrutura.

O sistema apresentado acarreta grande redução no tempo de execução da obra chegando a substituir a média de vinte meses dos sistemas convencionais por um tempo médio de seis meses. Além disso, a qualidade de acabamento e resistência do produto final quando comparados ao sistema convencional é imensurável. Por conta de seus aspectos positivos, o sistema tem sido bastante difundido no Brasil havendo várias unidades construídas, sendo 12 somente no estado do Espírito Santo, além de outras unidades nos estados da Bahia, Pará, Tocantins e Paraná.

Ainda em termos de custo/benefício é possível citar: 
- o menor tempo de execução da obra e, consequentemente, de início do funcionamento da unidade, o que possibilita que os presos sejam rapidamente retirados de locais inadequados e superlotados;

- a redução do contingente de agentes penitenciários necessários para operar o sistema, uma vez que além da pré-fabricação do ambientes adota-se também um sistema automatizado para o controle de abertura de celas. Assim, o investimento inicial em um sistema construtivo com mais qualidade e eficiência promove, já na entrada em operação da unidade, uma diminuição de seus custos mensais, segundo dados de avaliação técnica e da relação custo e benefício do sistema apresentados ao ministério da justiça em 2007.

Apesar das vantagens apresentadas, por se basear num método construtivo norteamericano, o sistema apresenta inadequações em sua implementação no Brasil. Um exemplo claro deste equívoco de aplicação está relacionado à ausência de aberturas para ventilação nas celas, sendo estas dotadas de seteiras - pequenas esquadrias à base de placas de policarbonato com $12 \mathrm{~cm}$ de espessura - que permitem apenas a passagem da luz. Na tentativa de solucionar o problema, algumas unidades federativas adotaram a utilização de exaustores nos módulos de vivência com o intuito de retirar o ar quente do ambiente e proporcionar maiores condições de conforto aos agentes e reeducandos.

Não é possível apresentar maiores detalhes com relação a custo de execução e especificações do sistema em questão, dada a dificuldade na obtenção de projetos e detalhamentos técnicos. A política de sigilo de projetos e a não divulgação de documentos gráficos nos processos licitatórios envolvidos na construção de unidades penais têm se mostrado fator de grande empecilho no desenvolvimento de pesquisas neste setor.

\subsection{Sistema B}

Também baseado na utilização de elementos pré-fabricados de concreto, o sistema B configura uma tipologia arquitetônica conhecida como poste telegráfica ou ainda espinhade-peixe (Figura 7).

\section{Figura 7 - Tipologia poste telegráfico ou espinha-de-peixe}

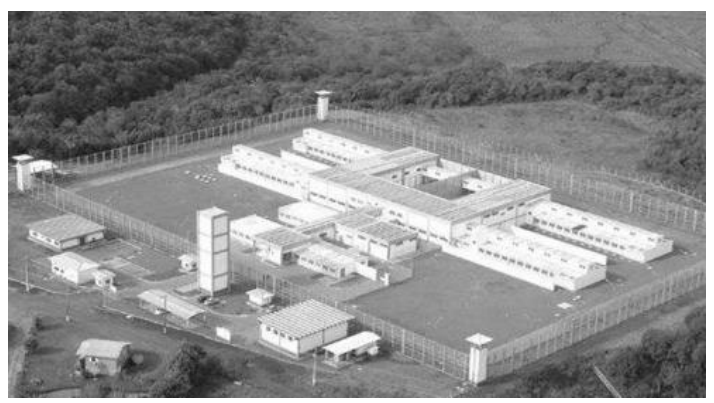

Fonte: VSISBRASIL (2014)

Desenvolvido totalmente em solo brasileiro o sistema em questão tem sido bastante difundido nos últimos dez anos, contando atualmente com aproximadamente 90 unidades construídas em todo o país. Dada sua difusão e aceitação no setor, o sistema passou a configurar não só um método construtivo como também uma tipologia arquitetônica conhecida como monobloco.

Ao contrário do sistema descrito anteriormente, o monobloco é composto por placas préfabricadas de alto desempenho cuja concretagem ocorre de maneira individual, havendo 
a necessidade de posterior montagem dos ambientes. $\mathrm{O}$ concreto utilizado não possui armadura de aço em seu interior, sendo esta substituída pela incorporação de fibras de polipropileno e fibras de vidro resistentes à álcalis (GRC). As placas podem ainda conter uma malha de fibra ótica que, conectada a um sistema de alarmes, consegue notificar qualquer tentativa de perfuração. Devido ao comportamento das fibras na mistura, o preenchimento das formas é realizado na horizontal.

O layout dos módulos também é diferenciado por conter uma passarela aérea entre os blocos de celas (Figura 8), através da qual são estruturados os componentes das instalações hidrossanitárias, é realizada a vigilância dos reeducandos e controle (manual) de abertura das celas (Figura 9).

\section{Figura 8 - Layout do sistema}

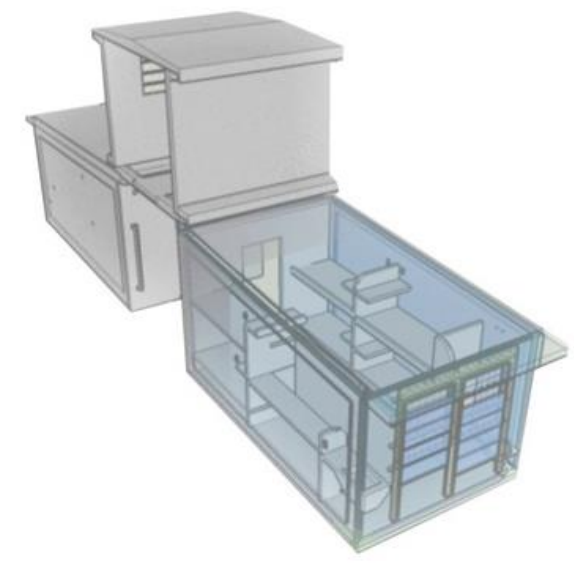

Figura 9 - Passarelas aéreas

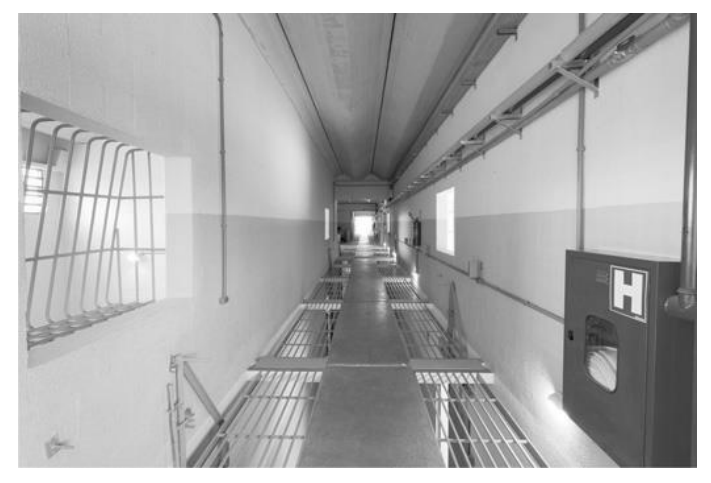

Fonte: VSISBRASIL (2014)

Apesar do custo inicial para implantação, o sistema tem sido visto como uma opção altamente viável por apresentar uma boa relação custo benefício a médio e longo prazo:

- a vida útil muito maior dos materiais utilizados no sistema construtivo, que podem ter durabilidade quatro vezes maior em relação a materiais comuns;

- a menor necessidade de manutenção, reformas e recuperações no prédio.

De fato, dados de um relatório de análise do sistema construtivo penitenciário à Secretaria de Estado da Justiça do Espírito Santo em 2007 indicam que o sistema em questão apresenta um custo médio inicial de $\mathrm{R} \$ 2.398,21$ (dois mil trezentos e noventa e oito reais e vinte um centavos) por metro quadrado e $\mathrm{R} \$ 44.587,11$ (quarenta e quatro mil quinhentos e oitenta e sete reais e onze centavos) por vaga, representando uma diferença de $6 \%$ a $28 \%$ a mais em relação aos sistemas convencionais.

Por outro lado, observou-se que para a construção de novas unidades os ganhos em tempo de execução giram em torno de $17 \%$ a $20 \%$ em relação às construções convencionais, podendo esse índice chegar até $50 \%$ quando se trata de ampliações de alas carcerárias ou módulos de vivência.

Com base na redução do tempo de obra, estima-se que num período de nove meses a menos de cinco anos, a diferença no custo inicial é eliminada. 
Em temos de propriedades, a estrutura apresenta resistência à compressão média de 80 $\mathrm{MPa}$, massa específica entre 1700 e $2100 \mathrm{~kg} / \mathrm{m}^{3}$ (mais leve que uma estrutura de concreto convencional), reduzido índice de vazios e uma expectativa de vida útil sem comprometimento físico três vezes maior em relação aos projetos convencionais.

Assim como no sistema anterior, este sistema é baseado na coordenação modular de ambientes apresentando certa limitação quanto à geometria das unidades (Figura 10).

Figura 10 - Possibilidades de tipologias com o sistema monobloco (vista em planta)

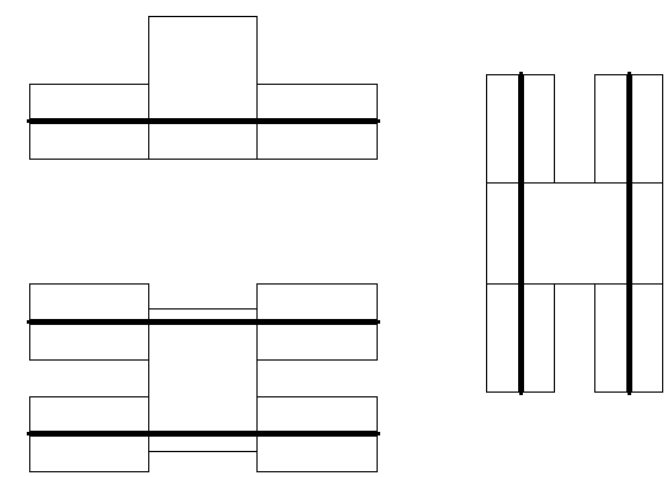

Fonte: Relatório de análise do sistema construtivo penitenciário. Ministério da Justiça (2007)

\section{CONSIDERAÇÕES FINAIS}

Conforme descrito, os avanços na pré-fabricação de construção de estabelecimentos penais focam nas questões de segurança e resistência dos materiais, porém, pouco temos avançado em relação a propostas inovadores do ponto de vista do partido arquitetônico. No entanto, a problemática da arquitetura penal brasileira não se restringe somente à construção de unidades arrojadas, sendo um tema complexo, com necessidade de âmbito interdisciplinar, que sugere a análise de diversos outros fatores, desde a concepção do projeto até a seleção de materiais e sistemas construtivos que deve ser baseada não somente em termos de desempenho estrutural.

Sobre questões de desempenho dos materiais, as soluções aqui apresentadas em termos de sistemas construtivos são satisfatórias em vários aspectos: segurança, agilidade de execução, qualidade da estrutura, racionalização da construção e outros. No entanto, é preciso ressaltar que a busca por sistemas inovadores não é suficiente, o custo de aplicação de novas tecnologias pode ser fator decisivo em sua escolha para aplicação, a falta de pesquisas e difusão dos sistemas de produção e aplicação destes sistemas acaba gerando uma barreira para a diminuição dos custos envolvidos.

Do ponto de vista do desenvolvimento de pesquisas na área, pode-se afirmar, com base na experiência obtida no desenvolvimento deste trabalho, que a falta de transparência dos processos e ausência de disponibilidade de dados, são os principais entraves quando se refere à obtenção $\mathrm{d}$ informações para análise de projetos e processos construtivos de edificações penais.

Ainda que as obras sejam públicas e que passem por processos licitatórios (com projetos básicos e falta de informações suficientemente detalhadas para a construção), a lei de acesso à informação não parece ser atendida nesta área. 
O espaço penal não é apenas punitivo, deve ser humanizador e acima de tudo ferramenta de reinserção social daqueles que transgrediram as convenções da sociedade. É evidente que a adoção de sistemas industrializados e racionalizados como os citados neste trabalho, se aplicados de maneira correta, só tendem a contribuir de maneira positiva para a resolução do problema de construção de novos estabelecimentos penais no que diz respeito a tempo de execução, desempenho e custo/benefício das estruturas construídas.

O projeto com pré-fabricados implica o conhecimento do projetista não só do produto final, mas também dos processos de fabricação dos elementos, do transporte, da montagem de suas ligações. Por esse motivo, o detalhamento dos projetos de arquitetura é de extrema importância para o bom desempenho desse sistema construtivo logo na concepção do projeto.

Nesse sentido, a transparência de informações e dados necessários para a construção de modelos de análise úteis para a observação e compreensão destes espaços e para a geração de novas tecnologias como estratégias consistentes ao planejamento espacial adequado e para a melhoria permanente de capacidades institucionais e locais, se configura em iniciativa importante para o salto qualitativo no processo de planejamento destes espaços.

\section{AGRADECIMENTOS}

Ao grupo PET Engenharia Civil da Universidade Federal de Alagoas e ao Núcleo de Pesquisas e Estudos de Projetos Especiais (NUPES) da Faculdade de Arquitetura e Urbanismo (FAU) da Universidade Federal de Alagoas.

\section{REFERÊNCIAS}

Anuário 2012 da Associação Brasileira da Construção Industrializada de Concreto (ABIC).

BRASIL, Ministério da Justiça. Apresentação do Programa Nacional de Melhoria do Sistema Prisional. Brasília, 2011.

BRASIL, Ministério da Justiça. Avaliação Técnica e da Relação Custo e Benefício. Departamento Penitenciário Nacional (DEPEN), DEPEN/DIRPP/CGPAI/COENA, Brasília, 2007.

BRASIL, Ministério da Justiça. Relatório de análise do sistema construtivo penitenciário. Nota técnica nº 335/2007 - DEPEN/DIRPP/CGPAI/COENA, Brasília, 2007.

DM Construtora. Projeto arquitetônico de unidade penal baseada no sistema construtivo A. 2011.

O GLOBO, Folhetim eletrônico. Brasil tem 55\% mais presos do que a média global. Disponível em: http://oglobo.globo.com/pais/brasil-tem-55-mais-presos-do-que-media-global.

PICCOLO, Sara. Técnicas Construtivas do Brasil Colônia. História e Teoria da Arquitetura III. Faculdade de Arquitetura e Urbanismo da Universidade Federal do Mato Grosso do Sul, Campo Grande, 2006.

VIANA, Lídia Quièto. A contribuição da arquitetura na concepção de edificações penais no Rio de Janeiro. Dissertação (Mestrado em Arquitetura) - Faculdade de Arquitetura e Urbanismo da Universidade Federal do Rio de Janeiro, Rio de Janeiro, mar. 2009.

VSISBRASIL. Sistema construtivo penitenciário.

Disponível em: <http://www.vsisbrasil.com.br/siscopen/brasil>. Acesso em: 31 mar. 2014. 